\title{
Arbor
}

\section{Derecho de familia y sociedad democrática}

\section{Luis Díez-Picazo}

Arbor CLXXVIII, 702 (Junio 2004), 313-321 pp.

El título de esta intervención, que es obra de los organizadores del ciclo, debo advertirlo, nos obliga, por lo menos a primera vista, a colocar el punto de partida de nuestras reflexiones en el momento de la entrada en vigor de la Constitución, toda vez que es en ella donde España se organiza como Estado social y democrático de derecho. Sin embargo, tal vez convenga ir un poco más atrás. Ante todo, porque en materia jurídica los cambios no se producen nunca milagrosamente por obra de los textos normativos. Sólo cuando éstos son recibidos por un terreno que está previamente abonado, tienen efectividad. Con ello lo que quiero decir, aunque parezca una paradoja, es que una gran parte de las reformas del Derecho de familia, que la Constitución terminó por consagrar, se encontraban preparadas por una larga evolución, cuyos hitos se pueden, en alguna medida, rastrear. Porque lo cierto es que quizás no exista, en el Derecho privado, ninguna otra parte que haya experimentado los embates de los cambios sociales como el Derecho de familia. Es verdad que el régimen político anterior, que adopta lo que algunos denominaron el nacionalcatolicismo, había tratado de retornar y de defender un sistema de familia mucho más tradicional, tratando de poner coto a una evolución que, por lo menos en los locos años veinte, había contemplado ya el avance del feminismo, reflejado en una novela de Víctor Marguerite, que lleva el expresivo título de «La Garçonne». Entre nosotros, la Segunda República había proclamado el derecho de voto de la mujer y, además, habían aparecido ya las primeras señoras que llegaban a ser ministros del gobierno. El franquismo supuso una ruptura y adoptó un modelo tradicional. Entresacaré alguno de mis recuerdos. El primero de ellos es la agenda de la Sección Femenina del Movimiento, dedicada a mujeres que 
eran mujeres de su casa, con recetas de cocina y cosas parecidas, de suerte que el prototipo y los roles eran de mujer de su casa-madre de familia. El segundo dato que abona la línea del nacionalcatolicismo es la abolición, en 1938, del matrimonio civil, que subsistirá sólo para aquellos que no profesaran la religión católica. Y el tercer dato es la prohibición del acceso de la mujer a puestos funcionariales relevantes que en la Segunda República habían quedado abiertos. Y así, en 1944 el Reglamento hipotecario y en 1946 el Reglamento notarial impidieron el acceso de la mujer a los cuerpos de notarios y registradores de la propiedad, aunque se permitió, de manera transitoria, que las que habían hecho antes alguna oposición sin éxito continuaran haciéndola. Sin embargo, nada de ello impidió la evolución social. Seguramente, en la evolución social los cambios que se producen en las estructuras económicas, por una parte, y, por otra, los cambios que se producen en el conjunto de las opiniones y de los valores que se profesan, tienen mucha más importancia que las normas jurídicas.

La evolución se reinició y hay un primer hito que seguramente ha de colocarse en el año 1958, fecha de una conocida reforma del Código Civil, impulsada por una, entonces, famosa abogada, Doña Mercedes Fórmica, por la cual fue llamada «La refórmica del Código Civil». Se introdujeron allí paliativos en materia de separación de los cónyuges, se suprimió el depósito antes necesario para que una mujer casada demandara la separación y se exigió el consentimiento uxorio para la disposición de bienes inmuebles y establecimientos mercantiles de carácter ganancial. Un segundo hito debe ser colocado en el año 1961, fecha en que, fomentada desde la Dirección General de Asociaciones de la Secretaría General del Movimiento, se impulsó y, finalmente, se aprobó una ley llamada de derechos políticos, profesionales y de trabajo de la mujer que suprimió una gran parte de las discriminaciones que la política inicial del régimen franquista había ido introduciendo, lo cual puede llevarnos a la conclusión, fácil de adoptar, de que ningún régimen político puede, finalmente, detener la evolución social. Es cierto que en esa Ley de 1961 todavía subsistían algunas limitaciones, sobre todo en lo que se refiere a la capacidad de acceso de la mujer a cargos y puestos públicos, porque quedaron sin abrir la carrera judicial y los empleos en las fuerzas armadas, que tuvieron que esperar ocasión mejor, que, según mis recuerdos, no llegó hasta el momento inmediatamente anterior, o posterior a la Constitución de 1978.

En todos esos años hubo también un trasiego constante de reformas legales de la institución de la adopción. Se suele decir, al estudiar la materia, que en el siglo XIX se la consideraba como algo casi ignoto y el có- 


\section{Derecho de familia y sociedad democrática}

digo la reguló con perfiles muy estrictos. La presión social, que continuó después, condujo a la regla o principio adoptio natura imitatur y, en consecuencia, a dotar a los hijos adoptivos de un estatuto prácticamente idéntico al de los hijos por naturaleza, aunque, todavía en esos años, se hiciera la reforma introduciendo dos formas de adopción, plena y menos plena, que después terminaron por desaparecer. Al mismo tiempo que la equiparación completa en la filiación formaba parte también de las aspiraciones de los adoptantes que se rompieran totalmente los vínculos preexistentes con lo que hoy se llamaría familia biológica del adoptado y que se restringiera, también lo más posible, cualquier pretensión de anulación o revocación de la adopción.

Dentro de este conjunto de recuerdos y de fechas, hay un momento, que, por lo menos para mí, tiene un carácter especialmente significativo. En el año 1972, por consiguiente todavía en los años del régimen del General Franco, su Ministro de Justicia, que era el señor Oriol, constituyó, en el seno de la Comisión General de Codificación, donde a mí me llevó Antonio Hernández-Gil que entonces la presidía, una sección especial de reforma del Derecho de familia. Quiero decir con ello que la necesidad de una reforma del Derecho de familia era sentida, no diré imperiosamente, pero sí con una cierta urgencia por la sociedad, hasta el punto de que el Ministerio de Justicia adoptó aquella decisión tres años antes de periclitar aquél régimen político y seis años antes de la promulgación de la Constitución.

Puedo dibujar las líneas generales de aquellos trabajos y puedo decir, muy resumidamente que dentro de la sección especial, había un grupo que trataba de articular un sistema civil de igualdad jurídica de los cónyuges dentro del matrimonio y dentro de la sociedad conyugal; otro que trabajaba en materia de filiación buscando la completa igualdad jurídica de los hijos cualquiera que fuera su origen; y un tercero que estaba tratando de esbozar una legislación de divorcio. No puedo decir si los que trabajaban en ese último tema eran zahoríes de un futuro lejano o se creían razonablemente que sus propuestas o proyectos podían llegar a entrar en vigor dentro de un tiempo razonable. En el fondo, creo también que para la supervivencia de aquel régimen político dar cauce a determinadas aspiraciones de movimientos sociales, sobre todo feministas, no representaba ningún peligro notable y, además, como ya he dicho, todo ello era una consecuencia del desarrollo económico que nuestro país había experimentado a lo largo de los años sesenta, que ejercía un notable influjo en las condiciones sociales y en las aspiraciones de muy destacados grupos. 
Las mujeres casadas (porque las solteras no debían tener ya mayores problemas desde el punto de vista jurídico) continuaban sintiendo como opresivo un sistema legal que exigía las licencias maritales para llevar a cabo cualquier tipo de actos jurídicos por muy anodinos que fueran o que las consideraba incapaces para contratar, como todavía decía el art. 1.262 del Código Civil. Es verdad que la vida ordinaria solía ir por un lado y los preceptos legales por otro hasta el momento en que había que toparse con alguna administración, pública o privada, que era con frecuencia especialmente rigurosa, como ocurría con los bancos o con los notarios. Hubo, pues, que proceder con una cierta urgencia a organizar un proyecto de ley en que se adoptaran tres tipos de medidas: la supresión de toda clase de licencias maritales, con el reconocimiento pleno de la capacidad de obrar de la mujer casada y la coparticipación de ésta en la gestión y disposición de los bienes comunes; lo que podríamos llamar la ruptura del principio de unidad jurídica de la familia, que significa que cada familia está regida por un mismo ordenamiento jurídico y tiene, para ello, la misma nacionalidad, reconociendo que los cónyuges pueden tener tras el matrimonio nacionalidades distintas; y un sistema paccionado para modificar el régimen económico por la vía de las capitulaciones postnupciales, aboliendo el principio, estatuido en el código, de que los capítulos eran siempre prenupciales e inmodificables, pues se consideraba que la vía capitular era un modo posible de aliviar las tensiones y el número de los pleitos surgidos de los conflictos conyugales, vulgarmente llamados pleitos de separación. Ese proyecto hubo que organizarlo con una cierta urgencia porque el año 1975 había sido declarado por las Naciones Unidas «Año Internacional de la Mujer» y los grupos de presión querían que la ley se aprobara en ese mismo año por las Cortes, que eran todavía Cortes orgánicas, por llamarlas así.

El proyecto no tuvo ningún tipo de dificultad y fue casi de inmediato aprobado, convirtiéndose, según quiero recordar, en la Ley de 2 de mayo de 1975. Los miembros de aquellas Cortes no sólo dieron su aprobación al proyecto, sino que urgieron al gobierno para que completara las reformas y le dieron un mandato para que llevara a buen puerto la completa igualdad jurídica de los cónyuges dentro del matrimonio. En la penumbra habían quedado todavía las otras dos líneas sobre las que la Comisión General de Codificación trabajaba, como eran la regulación del divorcio y la completa igualdad de los hijos cualquiera que fuera su filiación.

Por eso hay que volver a insistir en la gran importancia que tienen las evoluciones sociales, que muchas veces son más importantes que los mismos textos legales e incluso que los constitucionales. Se puede recordar, 
en este sentido que en la Constitución española de 1931, había existido ya una regla sobre la igualdad de todos los hijos con independencia de su filiación, que en aquellos años se quedó poco más o menos como letra muerta, porque los operadores jurídicos continuaron diciendo que la Constitución tenía un simple alcance programático, que la hacía ineficaz mientras no se dictaran las leyes de desarrollo. En 1978, los vientos habían cambiado de dirección y se adoptó de inmediato la idea, surgida en la pos-guerra de 1945, según la cual la Constitución es un Corpus iuris con eficacia inmediata, por lo menos en algunos terrenos, de manera que cualquier tentativa, que alguna hubo, de retornar a la idea del carácter meramente programático de la Constitución, quedó segada de raíz.

Los datos constitucionales de los que debe básicamente partirse, para definir lo que era el objeto de esta disertación, son básicamente dos, los arts. 32 y 39 .

En el art. 32, la Constitución dice que «El hombre y la mujer tienen derecho a contraer matrimonio con plena igualdad jurídica». La expresión «derecho a contraer matrimonio» es seguramente elíptica, porque no se puede considerar como un derecho subjetivo en abstracto. Uno no lo ejercita si no encuentra con quien y, aunque lo encuentre, tampoco existe un derecho a contraer matrimonio, porque el hecho de celebrar un matrimonio es más bien un producto de la libertad y, en este sentido, de su traducción jurídica que es la capacidad de obrar. Sin embargo, el reconocimiento constitucional del ius connubii, como a veces se le ha llamado, posee desde el punto de vista constitucional un alcance importante. Ante todo, hay una garantía institucional de una institución llamada matrimonio a la que la Constitución recoge y ampara, porque cumple una importante función social. Además, se encuentra la idea de que a esa institución llegan uniéndose un hombre y una mujer. La tercera idea es que, de acuerdo con el sistema constitucional, entre el hombre y la mujer unidos en matrimonio debe existir una plena igualdad jurídica. Finalmente, el art. 32 remite a la ley ordinaria la regulación de las «formas de matrimonio». En este punto hay que decir que lo remitido a la regulación legal son las formas y no los tipos, pues tipo hay uno solo. Las variantes son formas de expresión del llamado consentimiento matrimonial. En el régimen jurídico-político inmediatamente anterior se propendió a admitir la existencia de dos tipos, matrimonio canónico y matrimonio civil, y se vivía bajo la idea del predominio y la primacía del matrimonio contraído de acuerdo con el Derecho de la Iglesia católica, quedando el matrimonio civil como subsidiario para aquellos que no profesaran la mencionada religión. A partir de 1978 se entendió, sin problemas, que, aunque no 
existía un mandato constitucional de matrimonio civil obligatorio, el sistema de la Constitución era de libre opción respecto del modo de prestación del consentimiento, que recae sobre un único tipo de institución.

$\mathrm{El}$ art. 32 remite también a la ley ordinaria la edad para contraer matrimonio, los derechos y deberes de los cónyuges, las causas de separación y disolución y sus efectos. No ofrece dificultades especiales entender que, al remitir a la ley ordinaria las llamadas «causas de disolución», quedaba abierto el camino para una ley de divorcio.

El segundo de los artículos, había dicho es el art. 39. Según él «Los poderes públicos aseguran la protección social, económica y jurídica de la familia». El precepto añade que «Los poderes públicos aseguran, asimismo, la protección integral de los hijos, iguales éstos ante la ley con independencia de su filiación, y de las madres, cualquiera que sea su estado civil». El precepto concluye diciendo que «La ley posibilitará la investigación de la paternidad» y que «Los padres deben prestar asistencia de todo tipo y orden a los hijos nacidos dentro o fuera del matrimonio, durante su minoría de edad y en los demás casos en que legalmente proceda».

Es muy difícil, a partir de estos datos, llegar a la conclusión de que existe un concepto constitucional de familia. Si bien se mira, ocurre con familia, como ocurre con matrimonio o con propiedad privada o con tantas otras palabras jurídicas que la Constitución utiliza tomándolas en préstamo del metalenguaje de los juristas y del acervo de ideas que éstos tenían sobre las instituciones en el momento de promulgarse el texto constitucional.

A mí me parece que familia presupone generaciones sucesivas. En algún momento, en un prólogo que redacté para un libro de la profesora Roca Trías, apunté la idea de que se podía parafrasear un viejo brocardo escolástico que en materia de asociaciones dice tria faciunt collegia (hacen falta tres para que exista una asociación y no bastan dos), diciendo tria faciunt familia. Solamente cuando hay tres existe una familia y el tercero pertenece a una generación subsiguiente. Frente a esto se me podrá decir, y creo que la objeción es correcta, que existen sin duda y que sin duda debe ser considerado como familia lo que algunos han llamado relaciones segmentarias, es decir, un solo progenitor relacionado con su progenie. Progenitor e hijo forman familia y no hay tres sino solamente dos. Por eso he dicho antes que familia exige la relación intergeneracional y que familia, básicamente, en mi opinión, son hijos. Y esto parece desprenderse del artículo 39, que, cuando habla de protección de la familia, está mencionando, básicamente, a los hijos y a los padres. El matrimonio pertenece, sin duda, al Derecho de familia pero sólo como un 


\section{Derecho de familia y sociedad democrática}

momento que me atrevería a llamar fundacional, porque los matrimonios parece que se celebran a la espera de los hijos. Es verdad que estas esperas en los tiempos que corren se multiplican por muchos años, pero que la idea de hijos está presente en la idea institucional del matrimonio es algo de lo que no cabe duda, aunque también se pueda decir que la ley, arrancando de tradiciones canónicas, admite los matrimonios estériles siempre que la impotencia sea generandi y no coeundi, y los llamados matrimonios blancos de personas de edad avanzada.

En la idea de familia del art. 39 de la Constitución por las mismas razones antedichas no está sólo la familia fundada en el matrimonio. He dicho que el matrimonio es fundacional de la familia, pero de ahí no deduzco que sea la única vía de fundación. Todavía en el año 1979 en unas jornadas celebradas en el Centro de Estudios Sociales del Valle de los Caídos, se sostuvo que familia en el sentido del art. 39 de la Constitución era sólo la familia llamada anteriormente legítima y la familia fundada en el matrimonio. A mí me parece que, después de volver a leer: «los padres deben prestar asistencia de todo orden a los hijos nacidos dentro y fuera del matrimonio», las cosas aparecen perfectamente claras. Es el mismo artículo que acaba de hablar la protección integral de los hijos, iguales éstos ante la ley con independencia de su configuración. Y es el que se ha abierto con la idea de familia.

Me gustaría todavía esquematizar algunos puntos. El primero de ellos está ya expuesto: es el estrechamiento de la idea de familia que sociólogos y juristas habíamos ya señalado. Dos relaciones básicas: la relación entre los progenitores y la relación de filiación. Por consiguiente, es la pareja con sus hijos y, además, hay que añadir, con los hijos mientras éstos no han alcanzado el grado de desarrollo suficiente para vivir la vida por su cuenta, porque, a partir de ese momento, sus relaciones familiares pueden ser afectivas pero no son en puridad relaciones jurídicas. De aquí se deduce que el papel de lo que el Código civil llama parentesco es casi un papel residual que en los códigos civiles es difícil de rastrear, aunque en algunas leyes forales, como las aragonesas o las navarras, se regula una llamada junta de parientes que es un llamamiento a los parientes para ejercitar papeles sustitutorios de la patria potestad. El parentesco, básicamente, sólo tiene como efecto un llamamiento sucesorio abintestato a falta de ascendientes y de descendientes. Sin embargo, tengo que anotar que curiosamente ahora aparece o reaparece una sociedad de abuelos. No lo digo sólo porque uno los vea muchos días, yo que vivo enfrente de un colegio público, en el invierno madrileño, que no es que sea muy frío, pero que no resulta especialmente acogedor, ir a reco- 
ger a los nietos o cumplir algunas otras funciones específicas del hogar familiar. No lo digo sólo por eso, lo digo también porque se nos amenaza, en estos días, con lo que yo llamo la ley tonta del Ministro Zaplana que quiere hacer reaparecer los abuelos en el Código Civil. Digo hacerlos reaparecer, no hacerlos aparecer, porque por allí nunca estuvieron. Efectivamente en el Código Civil ustedes encuentran un precepto en virtud del cual no pueden impedirse las relaciones del hijo con otros parientes o allegados y uno supone fundadamente que los abuelos están dentro de la fórmula «otros parientes o allegados». Sin embargo, esta ley se empeña en decir «los abuelos y otros parientes o allegados» con gran entusiasmo de los lectores que mandan cartas a los periódicos diciendo que ya era hora de acordarse de los abuelos como si no estuvieran perfectamente recordados aunque no fuera nominatim. Sin embargo, se cambia el sentido que el precepto tenía. Porque el precepto estaba tratando de contemplar el interés del hijo -del hijo-nieto quiero decir-. Entre paréntesis diré que ese interés del hijo es una guía para los jueces, en los casos que tengan que tomar decisiones en relación con problemas de conflictos familiares, de crisis matrimoniales, en la adopción o en cosas parecidas. El Derecho de familia parece dirigido sobre todo hacia el mejor interés del hijo, probablemente porque tenemos un pobre concepto de la sociedad en la que vivimos, aspiramos a mejorarla y comprendemos que sólo la mejoraremos en nuestros hijos, lo cual continúa siendo, habrá que decirlo, otra vana esperanza porque uno al final sabe perfectamente que la sociedad de nuestros hijos, la vuestra o la de los vuestros, no será mucho mejor que la que nosotros tenemos, porque hay cosas que están implícitas en la condición humana. El segundo problema que esta ley -la ley tonta de $\mathrm{Za}$ plana-suscita, es que menciona también a los abuelos en los preceptos del Código Civil dictados para los casos de separación, nulidad y divorcio donde dice que el juez en casos excepcionales puede privar a ambos padres de la patria potestad y entonces designar tutor a un pariente o a una institución ad hoc y ahora dice los abuelos, los parientes y una institución ad hoc como si los abuelos no fueran parientes y no hubieran estado mencionados antes. Y hay un tercer punto donde esta ley de abuelos trata de introducirse. Exige que en los convenios reguladores de los supuestos de separación, nulidad y divorcio los cónyuges que adoptan tales convenios reguladores establezcan también el derecho de visitas de los abuelos. Lo cual, si bien se mira, es poner una bomba de relojería al convenio regulador, porque los que se están separando pueden llegar a ponerse de acuerdo sobre sus bienes (el piso, el coche y las cuentas bancarias), pero como tengan que ponerse de acuerdo en las visitas de la 


\section{Derecho de familia y sociedad democrática}

suegra el acuerdo zozobrará. Dejo simplemente la idea de la reaparición de los abuelos, lo cual a lo mejor les gustará a D. Benito Pérez-Galdós y a José Luis Garci. Al primero porque escribió la novela, pequeña novela y al segundo porque escribió la película sobre el papel de los abuelos.

Para concluir, me parece conveniente señalar el final de un pretendido ciclo de publificación del Derecho de familia, que tiene raíces muy antiguas. Creo que era Cicerón el que hablaba ya de seminarium rei publicae y de la relación entre la familia y la res publica, que reaparece curiosamente en algunas fórmulas prefascistas donde se pretendía la intermediación entre el individuo y el Estado a través de grupos intermedios entre los cuales se encontraba la familia. A los más viejos de entre nosotros les recordará el eslogan «familia, municipio y sindicato», por más que sean cosas bastante heterogéneas, como intermediadores de la relación entre individuo y el Estado en la llamada democracia orgánica, como si a la democracia de verdad hubiera que ponerle algún tipo de adjetivos. Era todavía frecuente en los libros de Derecho civil de los años cincuenta y sesenta traer a colación la obra de Antonio Cicu, a quien he citado entre los prefascistas italianos, que era de 1914, sobre la relación entre el Derecho de familia y el Derecho público. Ese intento tenía más de retórica que de otra cosa, pero hoy es un ciclo que podemos considerar completamente cerrado y agotado. Sin embargo, no debemos perder de vista el incremento de controles y de intervenciones de carácter público sobre el ejercicio de los derechos y de las potestades familiares. Y así tenemos administraciones, especialmente administraciones autonómicas, dedicadas a la atención y al cuidado de los niños en situaciones de cualquier tipo de abandono que además controlan las formas de ejercicio de la patria potestad, la ponen en cuestión y la suprimen siempre que consideran que así se debe hacer. 